\title{
Evaluation of patients with a recent clinical fracture and osteoporosis, a multidisciplinary approach
} Bianca Dumitrescu*1,2, Svenjhalmar van Helden ${ }^{3}$, Rene ten Broeke ${ }^{4}$, Arie Nieuwenhuijzen-Kruseman ${ }^{5}$, Caroline Wyers $^{6}$, Gabriela Udrea², Sjef van der Linden ${ }^{1}$ and Piet Geusens ${ }^{1,7}$

Address: ${ }^{1}$ Department of Internal Medicine, Subdivision of Rheumatology, University Hospital, Maastricht, The Netherlands, ${ }^{2}$ Department of Rheumatology, University of Medicine and Pharmacy 'Carol Davila' Bucharest, Romania, ${ }^{3}$ Department of Trauma Surgery, University Hospital, Maastricht, The Netherlands, ${ }^{4}$ Department of Orthopaedic Surgery, University Hospital, Maastricht, The Netherlands, ${ }^{5}$ Department of Internal Medicine, Division of Endocrinology, University Hospital, Maastricht, The Netherlands, 'Epidemiology, Maastricht University, The Netherlands and ${ }^{7}$ Biomedical Research Centre, University Hasselt, Belgium

Email: Bianca Dumitrescu* - bia1mar@yahoo.com; Svenjhalmar van Helden - s.vanhelden@surgery.azm.nl; Rene ten Broeke - rbr@sort.azm.nl; Arie Nieuwenhuijzen-Kruseman - a.kruseman@intmed.unimaas.nl; Caroline Wyers - caroline.wyers@epid.unimaas.nl; Gabriela Udrea - gabiudrea@yahoo.com; Sjef van der Linden - sli@sint.azm.nl; Piet Geusens - piet.geusens@scarlet.be

* Corresponding author

Published: 5 August 2008

BMC Musculoskeletal Disorders 2008, 9:109 doi:10.1186/1471-2474-9-109

This article is available from: http://www.biomedcentral.com//47/-2474/9/109

(c) 2008 Dumitrescu et al; licensee BioMed Central Ltd.

This is an Open Access article distributed under the terms of the Creative Commons Attribution License (http://creativecommons.org/licenses/by/2.0), which permits unrestricted use, distribution, and reproduction in any medium, provided the original work is properly cited.
Received: 20 November 2007

Accepted: 5 August 2008

\begin{abstract}
The aetiology of osteoporotic fractures is multifactorial, but little is known about the way to evaluate patients with a recent clinical fracture for the presence of secondary osteoporosis.

The purpose of this study was to determine the prevalence of contributors to secondary osteoporosis in patients presenting with a clinical vertebral or non-vertebral fracture. Identifying and correcting these contributors will enhance treatment effect aimed at reducing the risk of subsequent fractures.

In a multidisciplinary approach, including evaluation of bone and fall-related risk factors, 100 consecutive women $(n=73)$ and men $(n=27)$ older than 50 years presenting with a clinical vertebral or non-vertebral fracture and having osteoporosis $(T$-score $\leq-2.5)$ were further evaluated clinically and by laboratory testing for the presence of contributors to secondary osteoporosis.

In 27 patients, 34 contributors were previously known, in 50 patients 52 new contributors were diagnosed (mainly vitamin D deficiency in 42 ) and 14 needed further exploration because of laboratory abnormalities (mainly abnormal thyroid stimulating hormone in 9). The 57 patients with contributors were older (7I vs. 64 yrs, $\mathrm{p}<0.0 \mathrm{I})$, had more vertebral deformities $(67 \%$ vs. $44 \%, \mathrm{p}<0.05)$ and a higher calculated absolute $\mathrm{I} 0$-year risk for major $(\mathrm{I} 6.5 \mathrm{vs.} 9.9 \%, \mathrm{p}<0.0 \mathrm{I})$ and for hip fracture $(6.9 \mathrm{vs.} 2.4 \%, \mathrm{p}<0.0 \mathrm{I})$ than patients without contributors. The presence of contributors was similar between women and men and between patients with fractures associated with a low or high-energy trauma.

We conclude that more than one in two patients presenting with a clinical vertebral or non-vertebral fracture and BMD-osteoporosis have secondary contributors to osteoporosis, most of which were correctable. Identifying and correcting these associated disorders will enhance treatment effect aimed at reducing the risk of subsequent fractures in patients older than 50 years.
\end{abstract}




\section{Background}

Clinical vertebral and non-vertebral fractures are the most frequent fractures in patients presenting to the emergency ward of the hospital with a fracture [1]. After such fracture, patients are at increased risk for subsequent fracture and guidelines on osteoporosis advocate to evaluate patients presenting with a fracture in order to consider treament to reduce the risk of subsequent fractures [2].

One aspect of care identified within the management of fracture patients is the existence of contributors to secondary causes of bone loss [3]. Effective therapy requires that these contributors be recognised and when present managed appropriately $[3,4]$. If these conditions, however, are not recognized, treatment may be suboptimal or ineffective $[5,6]$.

Apart from bone mineral density (BMD)-osteoporosis ( $\mathrm{T}$ score less than or equal to -2.5$)[4,7,8]$ many risk factors are related to fracture risk, independently of BMD, such as clinical risk factors [9], fall risks [10], prevalent morphometric vertebral fractures (MVF) [11] and secondary osteoporosis [12]. There is increasing evidence that secondary osteoporosis is more prevalent than initially thought, not only in males, but also in females [13], but the true prevalence of contributors to secondary osteoporosis is unknown and no consensus regarding its evaluation is available [14].

Published data from referral centres for evaluation of osteoporosis indicate that 32 to $37 \%$ of women with low BMD have a history of other diseases or medications known to contribute to osteoporosis [3,15]. From 20\% up to $64 \%$ of patients had previously unknown secondary causes of osteoporosis that were only identified by laboratory testing [5]. In a study of patients with a clinical fracture, a high prevalence of contributors to secondary osteoporosis $(77 \%)$ was reported, but the study included only a limited number of patients with measured low BMD [16]. In a study of patients with a hip fracture, $80 \%$ had secondary causes of bone loss, mainly related to disturbed calcium and vitamin D homeostasis [6]. To date, we lack studies on the prevalence of contributors to secondary osteoporosis in other fracture populations.

The purpose of this study was to determine the prevalence of contributors to secondary osteoporosis, in the context of other bone- and fall-related fracture risks in patients presenting with a clinical vertebral or non-vertebral fracture and with a low BMD. Identifying and correcting contributors will enhance treatment effect aimed at reducing the risk of subsequent fractures.

\section{Methods}

In this prospective observational study, 100 consecutive and consenting patients older than 50 years, who presented between April 2005 and April 2006 with a clinical fracture at Maastricht University Hospital in the Netherlands, were included. After receiving medical treatment for the fracture, patients had a consultation with the fracture nurse. The fracture nurse provided information about the study and invited the patients to the Fracture and Osteoporosis Outpatient Clinic. Patients already on osteoporosis treatment $(44 / 1246,4 \%$ of all) or with pathological fractures due to malignancy or Paget's disease of bone were excluded from the analysis. Patients who agreed to participate were further referred to the program. Patients with osteoporosis according to World Health Organization (WHO) criteria for BMD [4] and in whom all laboratory data were available were included in the present study (Figure 1). This group was part of the evaluation of all consecutive patients presenting with a clinical fracture, of whom $35 \%$ had osteoporosis and $44 \%$ had osteopenia [1]. The medical ethical committee of the University Hospital Maastricht approved the study (MEC 03-194-5).

BMD in the left or right hip and the lumbar spine was determined using dual X-ray absorptiometry (DXA) with Hologic QDR 4500 Elite. Diagnosis of osteoporosis was based on the WHO criteria for BMD [4], as provided by the manufacturer for women and men. Patients were classified according to the lowest value of T-score in either total hip or spine.

All patients were interviewed for bone-related risk factors for fracture (previous non-vertebral and vertebral fractures, mother with fracture, body weight $<60 \mathrm{~kg}$, severe immobility, use of glucocorticoids) and fall-risk factors (falls in the past 12 months, use of assistive devices, sedative medication, activities of daily living, mobility, impaired vision, articular complaints, urine incontinency), according to the Dutch guidelines on osteoporosis [2] and fall prevention [10]. Additionally, data about vitamin $\mathrm{D}$ status (regular sun exposure, dietary intake and supplements), calcium intake $[17,18]$, height, history of height loss [19] and a description of the circumstances leading to the fracture (with specification of fall from a standing height or other trauma) were recorded.

Patients with T-scores $\leq-2.5$ were given a pre-planned set of laboratory tests that included erythrocyte sedimentation rate (ESR), haemoglobin, leucocytes and serum levels of creatinine, calcium, albumin, alkaline phosphatase, 25$\mathrm{OHD}_{3}$ and TSH. Calcium and creatinine were measured in a 24-hour urine collection. All laboratory analyses were performed in the same laboratory. Patients with osteoporosis and having the full set of evaluation were sent for a consultation with either a rheumatologist or an endo- 


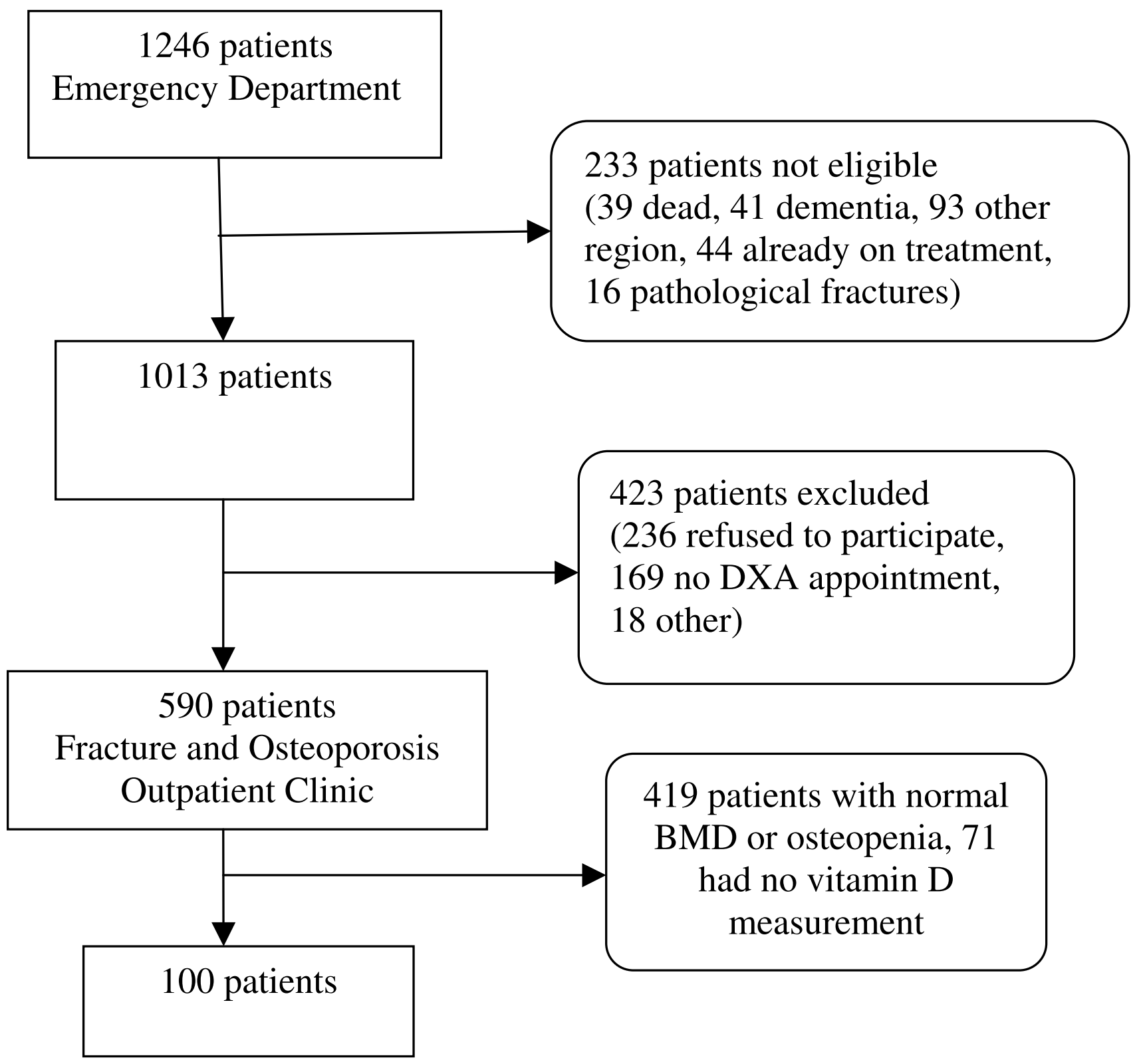

Figure I

Flow chart of patients included in the study (see text for details) in one year.

crinologist. The specialist decided further investigation and treatment. When clinically appropriate, additional tests were performed. The diagnosis of contributors to secondary osteoporosis was based on all data from the medical files. Renal insufficiency was defined with the cut-off value of creatinine clearance $\leq 40$ using the Cockroft Gault formula [20]. Vitamin D status was defined as severely deficient when values were $\leq 30 \mathrm{nmol} / \mathrm{L}$, deficient when between 30 and $\leq 50 \mathrm{nmol} / \mathrm{L}$, insufficient when values were between 50 and $\leq 75 \mathrm{nmol} / \mathrm{L}[21,22]$ and abnormally high when above $220 \mathrm{nmol} / \mathrm{L}$ [23]. Exploration for hypogonadism in men was considered when a morning serum testosterone level was below $12 \mathrm{nmol} / \mathrm{L}[24]$ and for thyroid disorders when TSH were outside the reference ranges (0.4-3.5 mU/L). Hyperparathyroidism was diagnosed when serum parathyroid hormone (PTH) levels were above $5.5 \mathrm{pmol} / \mathrm{l}$. Further exploration for hypercalciuria was considered when the total urinary calcium in a 24 hours collection exceeded $7 \mathrm{mmol} / \mathrm{d}$ and creatinuria indicated an appropriate collection (between 4.5 - 13.3 
mmol/hour) [25]. According to clinical judgement, patients suspected to have lactose intolerance had a lactose tolerance test [26].

Vertebral fracture assessment (VFA) $[27,28]$ by single Xray absorptiometry on the lateral spine images was performed to identify the presence of morphometric vertebral deformities (MVD). Images were saved in a digital format. Physician Viewer software (Hologic, USA) provided the tools necessary to perform quantitative vertebral morphometry. Visual assessment and measurements of the anterior, posterior and mid heights from T4 to L4 were performed twice, by a trained rheumatologist (BD). These assessments were inputted into a database. The observer was blinded from the results of the first measurements. The intra-observer coefficient of variation (ICC) at vertebral level for heights was 0.917 (95\% confidence interval (CI): 0.905-0.930, Cronbach's alpha 0.959). The arithmetic mean heights of the two measurements were used for calculation. The anterior-posterior ratio, the middleposterior ratio, the posterior-posterior ratio were calculated. Prevalent morphometric vertebral deformities (MVD) were defined according to the Genant grading [29]. Vertebral deformities were classified into three types (wedge, biconcavity, crush) and three grades (mild (any ratio $<20 \%$ ), moderate (any ratio between $25-40 \%$ ), and severe (any ratio $>40 \%$ )).

The WHO Fracture risk assessment tool (FRAX) was used to calculate the absolute 10 -year risk for major and for hip fractures in women and men [12].

Statistical analyses were performed using SPSS version 12.01. Categorical variables and proportions were analyzed using chi-square statistic. Odds ratio (OR) with $95 \%$ confidence intervals (95\% CI) were calculated based on the chi squares. One way Anova and chi-square statistics were used to analyze differences in continuous variables between subgroups. Observations were considered significant if two-sided p-values were $<0.05$.

\section{Results}

Of the 100 patients, 73 were women and were 27 men. Mean age was 68 years (standard deviation: 10 years, range: 50 to 90 years). Demographic data are summarized in Table 1. The majority of patients were Caucasian $(97 \%)$. Fractures were found at the following locations: clinical vertebral fractures $(n=4)$, clavicle $(n=3)$, pelvis $(n=2)$, humerus $(n=10)$, radius and/or ulna $(n=24)$, hand $(n=6)$, hip $(n=17)$, tibia/fibula/patella $(n=8)$ and foot $(n=21)$. Five patients had multiple simultaneous fractures and 80 patients had fractures after a fall from standing height.
A total of 86 contributors to secondary osteoporosis were diagnosed in 57 patients (Table 1 and 2). Contributors consisted of known medical conditions (34 in 27 patients) or newly diagnosed (52 in 50 patients). Seven patients had only known contributors, 20 had known plus a newly diagnosed contributor and 30 had only newly diagnosed contributors. One contributor was found in 32 (of whom 24 were vitamin D deficient), more than one contributor in 25 and 43 had none.

Based on serum levels of $25-\mathrm{OHD}_{3}, 11$ patients had severe deficiency, 31 were deficient and 31 had insufficient serum values. All were newly diagnosed. Serum levels of $25-\mathrm{OHD}_{3}$ could not be predicted by any of questions on vitamin $\mathrm{D}$ or by the sum of those questions. Calcium intake below $1200 \mathrm{mg}$ was reported in 86 patients. Only three patients had both a calcium intake above $1200 \mathrm{mg}$ and a serum $25-\mathrm{OHD}_{3}$ level above $75 \mathrm{nmol} / \mathrm{L}$ (Figure 2).

Five patients had secondary hyperparathyroidism, of which four were newly diagnosed (Table 2). Hyperparathyroidism was secondary to renal insufficiency in three cases and to low calcium intake in two cases. We found 14 patients with renal insufficiency, of which 6 were newly diagnosed. Three patients were known with hyperthyroidism, 1 new case of exogenous hyperthyroidism and 1 new case of hypothyroidism was detected. One new case of lactose intolerance was diagnosed. Further contributors included anorexia nervosa in 2 women, documented hypogonadism in one men, pulmonary diseases in 5 patients (chronic obstructive lung disease and asthma), alcohol abuse in 4 men, inflammatory rheumatic diseases in 3 patients ( 2 with rheumatoid arthritis and 1 with giant cell arteritis) and 3 with severe immobility. Most of these patients did not receive preventive measures for osteoporosis prior to the fracture and were thus not recognized as having a contributor to secondary osteoporosis before the fracture occurred.

Other laboratory abnormalities that required further exploration were found in 14 patients ( 18 abnormalities in total), including exogenous hypervitaminosis D ( $\mathrm{n}=$ $1)$, hypercalciuria $(n=3)$, TSH outside normal ranges $(n$ =13) and low serum testosterone in one men (Table 3). Among the 9 patients being treated for hypothyroidism, one was over-treated while three were under-treated based on abnormal serum TSH levels. Among the 3 patients being treated for hyperthyroidism, two were under-treated while one was over-treated.

According to the Dutch guideline for osteoporosis 54 patients had clinical bone-related risk factors for fractures in addition to their current fracture (Table 4). A history of an additional clinical fracture after the age of 50 was present in 31 patients (two with a previous clinical spine 
Table I: Characteristics of the patient population $(\mathbf{N}=100)$

\begin{tabular}{|c|c|c|c|c|c|c|c|}
\hline $\begin{array}{l}\text { Variable } \\
\text { Median+/-SD }\end{array}$ & All patients & Women & Men & $\begin{array}{l}\text { Fragility } \\
\text { fracture }\end{array}$ & $\begin{array}{l}\text { High energy } \\
\text { trauma }\end{array}$ & $\begin{array}{l}\text { With } \\
\text { contributors }\end{array}$ & $\begin{array}{l}\text { Without } \\
\text { contributors }\end{array}$ \\
\hline Number & 100 & 73 & 27 & 80 & 20 & 57 & 43 \\
\hline Women/men (n) & $73 / 27$ & na & na & $66 / 14$ & $7 / 13^{* *}$ & $40 / 17$ & $33 / 10 * * *$ \\
\hline $\begin{array}{l}\text { Caucasian } \\
\text { ethnicity (n) }\end{array}$ & 97 & 94 & 27 & 79 & 18 & 55 & 42 \\
\hline Age (years) & $68 \pm 10$ & $70 \pm 9$ & $62 \pm 8^{*}$ & $69,1 \pm 9$ & $63.3 \pm 9 * *$ & $71 \pm 10$ & $64 \pm 7 * * *$ \\
\hline Weight (kg) & $66 \pm 13$ & $63 \pm 13$ & $73 \pm 11 *$ & $65,4 \pm 14$ & $68.8 \pm 11$ & $64 \pm 14$ & $69 \pm 11$ \\
\hline Spine T-score & $-2.88 \pm .91$ & $-2.94 \pm 0.79$ & $-2.73 \pm 1.17$ & $-2.9 \pm 0.92$ & $-2.8 \pm 0.83$ & $-2.85 \pm 0.97$ & $-2.93 \pm 0.82$ \\
\hline Hip T-score & $-1.92 \pm 0.9$ & $-2.13 \pm 0.92$ & $-1.37 \pm 0.70^{*}$ & $-2 \pm 0.87$ & $-1.6 \pm 1.09$ & $-2.1 \pm 1.00$ & $-0.66 \pm 0.63^{* * *}$ \\
\hline Hip Z-score & $-1.92 \pm 0.8$ & $-0.57 \pm 0.85$ & $-0.89 \pm 0.73$ & $-0.62 \pm 0.85$ & $-0.83 \pm 0.72$ & $-0.66 \pm 0.97$ & $-0.66 \pm 0.63$ \\
\hline $\begin{array}{l}\text { BMD spine } \\
(\mathrm{g} / \mathrm{sq} \mathrm{cm})\end{array}$ & $0.772+/-0.100$ & $0.756 \pm 0.085$ & $0.810 \pm 0.130 *$ & $0.765 \pm 0.103$ & $0.795 \pm 0.094$ & $0.776 \pm 0.109$ & $0.766 \pm 0.091$ \\
\hline BMD hip $(\mathrm{g} / \mathrm{sq} \mathrm{cm})$ & $0.718+/-0.395$ & $0.676 \pm 0.115$ & $0.825 \pm 0.107^{*}$ & $0.700 \pm 0.116$ & $0.779 \pm 0.160 * *$ & $0.695 \pm 0.143$ & $0.749 \pm 0.106$ \\
\hline $\begin{array}{l}\text { Calcium } \\
\text { intake(mg/day) }\end{array}$ & $852 \pm 432$ & $828 \pm 448$ & $915 \pm 389$ & $851 \pm 467$ & $854 \pm 266$ & $744 \pm 343$ & $993 \pm 497^{* * *}$ \\
\hline $\begin{array}{l}\text { Serum } 25 \mathrm{OH} \\
\text { vitamin } D(\mathrm{nmol} / \mathrm{L})\end{array}$ & $66 \pm 53$ & $67 \pm 60$ & $63 \pm 28$ & $63 \pm 57$ & $75 \pm 30$ & 42 & 0 \\
\hline $\begin{array}{l}\text { Creatinine } \\
\text { clearance }(\mathrm{ml} / \mathrm{min})\end{array}$ & $67 \pm 23$ & $62 \pm 20$ & $65 \pm 23$ & $65 \pm 23$ & $74 \pm 26$ & $45 \pm 18$ & $82 \pm 24 * * *$ \\
\hline $\begin{array}{l}\text { Fracture after fall } \\
\text { from standing } \\
\text { height }(n)\end{array}$ & 80 & 66 & 14 & na & na & 45 & 35 \\
\hline $\begin{array}{l}\mathrm{N} \text { of contributors } \\
\text { (n) }\end{array}$ & 86 & 62 & 24 & 70 & 16 & na & na \\
\hline $\begin{array}{l}\mathrm{N} \text { with } \\
\text { contributors (n) }\end{array}$ & 57 & 40 & 17 & 45 & 12 & na & na \\
\hline $\begin{array}{l}\mathrm{N} \text { with bone- } \\
\text { related fracture } \\
\text { risks }\end{array}$ & 54 & 42 & 12 & 44 & 10 & 33 & 21 \\
\hline $\begin{array}{l}\mathrm{N} \text { with fall-related } \\
\text { fracture risks }\end{array}$ & 79 & 57 & 22 & 65 & 14 & 46 & 33 \\
\hline $\begin{array}{l}\text { Time Go Up and } \\
\text { Go (min) }\end{array}$ & $8.6 \pm 7.9$ & $8.4 \pm 8.0$ & $8.9 \pm 8.0$ & $8.2 \pm 8.0$ & $9.8+/-8.0$ & $8.1+/-8.6$ & $9.2+/-7.1$ \\
\hline $\begin{array}{l}\mathrm{N} \text { with MVD } \\
<0.80 \\
\text { (n/n measured) }\end{array}$ & $53 / 93$ & $35 / 66$ & $18 / 27$ & $42 / 73$ & $11 / 20$ & $36 / 54$ & 17/39**** \\
\hline $\begin{array}{l}\mathrm{N} \text { with MVD } \\
<0.75\end{array}$ & 29 & 22 & 7 & 24 & 11 & 19 & 10 \\
\hline
\end{tabular}

${ }^{*} p<0.05$ women vs. men, ${ }^{* *} p<0.05$ between fragility fracture and high-energy trauma, ${ }^{* * *} p<0.05$ between group with and without contributor, $\mathrm{Na}$ : not applicable

fracture). Additionally, 12 had a mother that had suffered one or more fractures, 3 were severely immobilised, and $23 \mathrm{had}$ a low body weight $(60 \leq \mathrm{kg})$. One bone-related risk factor was found in 41 patients, 2 in 12 and 3 in one patient. According to the Dutch guideline for fall prevention, we found fall related risk factors in 79 of the patients: 22 patients had one risk factor, 21 had two risk factors, and 36 had more than two risk factors. An overlap between clinical bone related risk factors and fall related risk factors was present in 45 patients. The prevalence of clinical bone-related and fall-related risk factors was similar between patients that had documented contributors secondary osteoporosis and those who did not (50\% ver- sus $59 \%$ for clinical bone related risk factors and $79 \%$ versus $84 \%$ for fall-related risk factors for fractures).

VFA could be performed for 93 patients. Lateral spine images were not available in 7 cases due to severe scoliosis or other technical difficulties such as positioning patients with humerus fracture on the DXA table. On VFA, $57 \%$ of patients had a MVD, 31\% had more than one MVD and $31 \%$ had moderate and severe MVD.

The 57 patients with contributors to secondary osteoporosis were older ( 71 versus 64 yrs, $\mathrm{p}<0.01$ ) (Table 1 ). They had more of some fall risks (multi-medication use (13 
Table 2: Contributors to secondary osteoporosis identified in men and women $>50$ years with a recent clinical fracture $(N=100)$

\begin{tabular}{|c|c|c|c|c|c|}
\hline Contributors & Total & Known & Newly diagnosed & $\begin{array}{l}\text { Fragility Fracture } \\
(\mathbf{N}=\mathbf{8 0})\end{array}$ & $\begin{array}{l}\text { High-energy trauma } \\
(\mathbf{N}=20)\end{array}$ \\
\hline \multicolumn{6}{|l|}{ Endocrine disorders } \\
\hline Serum $25-\mathrm{OHD}_{3} \mathrm{~s} \leq 50 \mathrm{nmol} / \mathrm{l}$ & 42 & 0 & 42 & 37 & 5 \\
\hline $\begin{array}{l}\text { Hyperparathyroidism secondary to low calcium } \\
\text { intake }\end{array}$ & 2 & 0 & 2 & 1 & $\mathrm{I}$ \\
\hline Hyperthyroidism & 3 & 3 & 0 & 3 & 0 \\
\hline Hypogonadism (in men) & I & I & 0 & 0 & I \\
\hline Anorexia nervosa (in women) & 2 & 2 & 0 & 2 & 0 \\
\hline Diabetes mellitus & 5 & 5 & 0 & 4 & 1 \\
\hline \multicolumn{6}{|l|}{ Gastrointestinal disorders } \\
\hline Lactose intolerance & I & 0 & I & 0 & I \\
\hline \multicolumn{6}{|l|}{ Connective tissue disorders } \\
\hline Rheumatoid arthritis & 2 & 2 & 0 & I & 1 \\
\hline Giant-cell arteritis & I & I & 0 & I & 0 \\
\hline \multicolumn{6}{|l|}{ Renal disorders } \\
\hline $\begin{array}{l}\text { Renal insufficiency without secondary } \\
\text { hyperparathyroidism }\end{array}$ & 11 & 5 & 6 & 7 & 4 \\
\hline Renal insufficiency with secondary hyperparathyroidism & 3 & 3 & 0 & 3 & 0 \\
\hline \multicolumn{6}{|l|}{ Miscellaneous } \\
\hline Severe immobility & 3 & 3 & 0 & 3 & 0 \\
\hline Pulmonary diseases & 5 & 5 & 0 & 4 & 1 \\
\hline \multicolumn{6}{|l|}{ Medication and life style } \\
\hline Exogenous hyperthyroidism & I & 0 & 1 & I & 0 \\
\hline Alcohol abuse & 4 & 4 & 0 & 2 & 2 \\
\hline Total number of contributors $(N=86)$ & 86 & 34 & 52 & 69 & 17 \\
\hline $\begin{array}{l}\text { Total number of patients with contributors to } \\
\text { osteoporosis }(N=57)\end{array}$ & 57 & 27 & 50 & 45 & 12 \\
\hline
\end{tabular}

versus $3, \mathrm{p}<0.05$ ), restricted activities of daily living (34 versus $15, \mathrm{p}<0.05$ ) and disturbed vision (13 versus $3, \mathrm{p}<$ 0.05 ) (Table 4$)$ ). They had lower calcium intake (744 versus $993 \mathrm{mg}$, $\mathrm{p}<0.05)$ (Table 1 ) and more MVD (67\% versus $44 \%$, p < 0.05, OR: $=2.6,95 \% \mathrm{CI}:=1.1-6.0$ ) (Figure 3).

In contrast, the proportions of women (70 versus $77 \%$ ) and of patients with fragility fractures (79 versus $81 \%$ ) were similar between patients with and without contributors. There were also no differences in the prevalence of bone-related clinical risks (59 versus 50\%).

Based on the FRAX tool, patients with contributors had a higher calculated absolute 10-year risk for major (16.5 vs. $9.9 \%, \mathrm{p}<0.01$ ) and for hip fractures (6.9 vs. $2.4 \%$, p < $0.01)$.

Compared to patients with a high-energy trauma, patients with fragility fractures were older ( 69 versus 63 years), had better activities of daily living (43 versus 16 patients), and more osteoarthritis (44 versus 4 patients) (Table 1 and 3 ).

\section{Discussion}

In the 100 patients older than 50 years presenting with a recent clinical fracture and osteoporosis and referred by the surgeons to the rheumatologists in collaboration with the endocrinologists the prevalence of contributors to secondary osteoporosis was high: almost two out of three patients had one or more contributors most of which were correctable.

Our results show that many patients (27\%) had known contributors to secondary osteoporosis, a percentage similar to that of Tannenbaum et al. in women with postmenopausal osteoporosis who were seen in an osteoporosis referral centre (32\%) [3]. The categories of known contributors to secondary osteoporosis were globally similar as reported by Tannennbaum [3] (endocrine, gastrointestinal and inflammatory rheumatic and pulmonary diseases, severe immobility, alcohol abuse). One exception was glucocorticoid users who are presumably frequently referred to an osteoporosis clinic, but were not represented in our group of patients. In contrast to Tannenbaum, we performed the laboratory test set also in patients with already known contributors and 20 additional contributors were diagnosed in 20 patients (mainly low 25-OHD3, $n=14$ ). Presumably none of the patients with known contributors had received attention in the context of osteoporosis, as none had osteoporosis treatment or calcium and vitamin D supplements.

In the other, presumably healthy patients without known contributors, laboratory testing identified newly diag- 


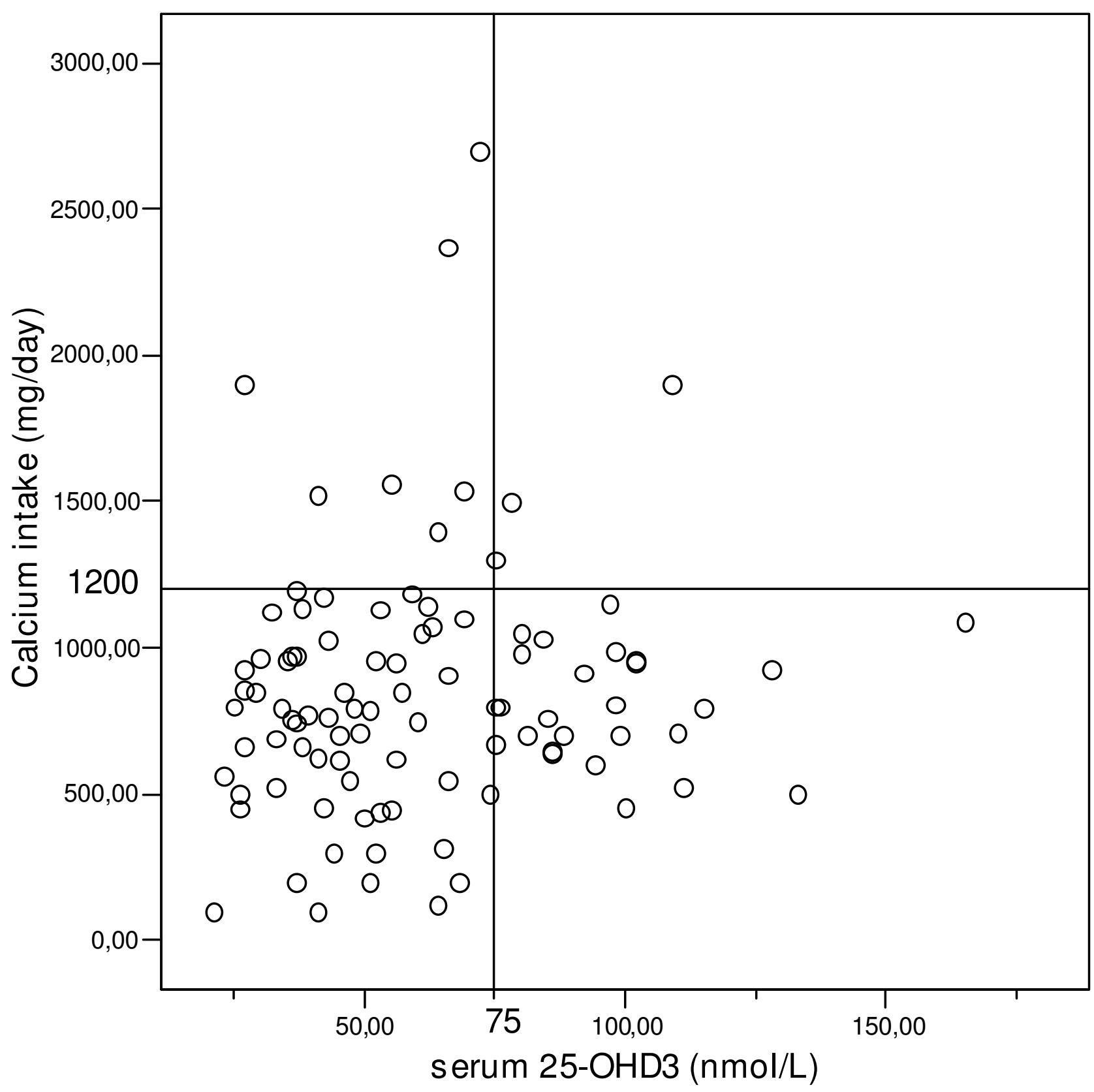

Figure 2

Calcium intake and serum serum levels of 25OHD3. Only 3 patients had sufficient intake of calcium and normal serum levels of $25-\mathrm{OHD} 3$.

nosed contributors to secondary osteoporosis in 30 more patients, mostly vitamin D deficiency and renal disorders. The number of patients with newly diagnosed contributors $(50 \%)$ was higher than reported by Tannenbaum et al. (33\%) and concerned mainly vitamin D deficiency, secondary hyperparathyroidism (to renal insufficiency and to low calcium intake), malabsorption and exoge- nous hyperthyroidism [3]. In contrast to Tannenbaum, we performed TSH not only in patients with a history of thyroid diseases, but in all patients, and were able to diagnose one new case of hypothyroidism.

Vitamin D status could not be identified by history, despite including four specific questions regarding vita- 
Table 3: Laboratory abnormalities that required further exploration in men and women more than $\mathbf{5 0}$ years of age with a recent clinical fracture $(N=100)$

\begin{tabular}{ll}
\hline Laboratory abnormality & Total \\
\hline Exogenous hypervitaminosis $\mathrm{D}(>220 \mathrm{nmol} / \mathrm{l})$ & $\mathrm{I}$ \\
Hypercalciuria in 24 hours urine & 3 \\
TSH $0.4-3.5 \mathrm{mU} / \mathrm{L}$ & 13 \\
$->3.5 \mathrm{mU} / \mathrm{L}$ & 10 \\
- treated hypothyroidism & 9 \\
$-\mathrm{TSH}<0.4 \mathrm{mU} / \mathrm{L}$ & $\mathrm{I}$ \\
$-\mathrm{TSH}>3.5 \mathrm{mU} / \mathrm{L}$ & 3 \\
- treated hyperthyroidism & 3 \\
$-\mathrm{TSH}>3.5 \mathrm{mU} / \mathrm{L}$ & $\mathrm{I}$ \\
$-\mathrm{TSH}<0.4 \mathrm{mU} / \mathrm{L}$ & 2 \\
Serum testosterone in men $<12 \mathrm{nmol} / \mathrm{L}$ (one measurement) & $\mathrm{I}$ \\
\hline Total number of patients & $\mathrm{I}$ \\
\hline
\end{tabular}

min D intake. It has been shown that there is only a modest relation between reported vitamin $D$ intake from an extensive dietary questionnaire and serum levels of 25OHD3 [30]. In our study a wide spectrum of levels of serum 25-OHD3 were found, from severely deficient to normal. There is still no consensus about how much vitamin D supplements are required to normalise serum levels. Some propose a unique dose of $800 \mathrm{IU} /$ day together with $1000-1200 \mathrm{mg}$ calcium/day to achieve $50 \mathrm{nmol} / \mathrm{L}$ $[31,32]$. Others state that a unique dose of 800-1600 IU/ day would normalize serum levels to $>75 \mathrm{nmol} / \mathrm{L}[33,21]$. As patients with low serum levels of $25-\mathrm{OHD}_{3}$ require, at least temporarily, high doses of vitamin $\mathrm{D}$ supplements while those with normal levels require less or none [34], measuring serum 25-OHD3 levels is helpful in patients with osteoporosis in order to decide about appropriate vitamin D supplementation [3].

The calcium homeostasis was further compromised by the low calcium intake $(<1200 \mathrm{mg} /$ day $)$ in most patients, resulting in secondary hyperparathyroidism in 2, and only $3 \%$ of the patients had both adequate calcium intake and vitamin D status. Correcting these combined deficiencies has been demonstrated to reduce fracture risk, at least in institutionalized elderly women [35] and to reduce the risk of falls [36]. Calcium and vitamin D supplementation are thus needed in most patients presenting with a fracture and osteoporosis. However, supplementation with calcium and vitamin D alone is an insufficient measure in patients with osteoporosis, as drug therapy for osteoporosis has been shown to reduce the risk of fractures on top of correcting such deficiencies. Our data, together with those of Edwards et al. [6] indicate that calcium and vitamin D deficiency is frequently present in patients presenting with a fracture, and that these deficiencies need to be identified and corrected.

Interestingly, the presence of contributors was similar between women and men, and between patients with fractures associated with low or high-energy trauma, suggesting that evaluation for secondary contributors is indicated in women and men and after low or high-energetic trauma.

An additional 14 patients had laboratory abnormalities that required further investigation, mainly hypercalciuria, uncontrolled treatment of thyroid disorders and low tes-

Table 4: Clinical risks for fractures recorded in patients with a recent clinical fracture according to the Dutch guidelines

\begin{tabular}{|c|c|c|c|c|c|c|c|}
\hline CLINICAL RISKS OF FRACTURE & Total & Women & Men & Fragility fracture & High trauma & Contributors & No contributors \\
\hline Numbers of patients & 100 & 73 & 27 & 80 & 20 & 57 & 43 \\
\hline BONE RELATED RISK FACTORS & 54 & 42 & 12 & 44 & 10 & 33 & 21 \\
\hline History of clinical fracture after 50 years & 31 & 23 & 8 & 25 & 6 & 19 & 12 \\
\hline History of clinical vertebral fracture & 2 & I & 0 & 1 & 0 & 1 & 0 \\
\hline Mother with fracture & 12 & 9 & 3 & 10 & 2 & 8 & 4 \\
\hline Low body weight (<60 kg) & 23 & 20 & 3 & 18 & 5 & 15 & 8 \\
\hline Severe immobility & 3 & 3 & 0 & 3 & 0 & 3 & 0 \\
\hline Glucocorticosteroids user & 0 & 0 & 0 & 0 & 0 & 0 & 0 \\
\hline FALL RELATED RISK FACTORS & 79 & 57 & 22 & 65 & 14 & 46 & 33 \\
\hline Mobility: Time Get up and Go test & 24 & 21 & 3 & 20 & 4 & 12 & 12 \\
\hline $\begin{array}{l}\text { Previous falls: } 2 \text { or more falls in the } \\
\text { previous year }\end{array}$ & 27 & 22 & 5 & 23 & 4 & 15 & 12 \\
\hline $\begin{array}{l}\text { Medication use } \\
\text { (benzodiazepines, antiepileptics) }\end{array}$ & 16 & 14 & 2 & 14 & 2 & 13 & 3 \\
\hline Low activities of daily living & 49 & 38 & 11 & 43 & $16^{*}$ & $34 * *$ & 15 \\
\hline Osteoarthritis & 48 & 40 & 8 & 44 & $4^{*}$ & 25 & 23 \\
\hline Snellen score-visual acuity less than 0.4 & 16 & 8 & 8 & 14 & 2 & 13 & 3 \\
\hline Urinary incontinence & 19 & 17 & 2 & 19 & 0 & 13 & 6 \\
\hline
\end{tabular}

$*_{\mathrm{p}}<0.05$ between fragility fracture and high-energy traum fracture, $*^{*} \mathrm{p}<0.05$ between groups with and without contributors 


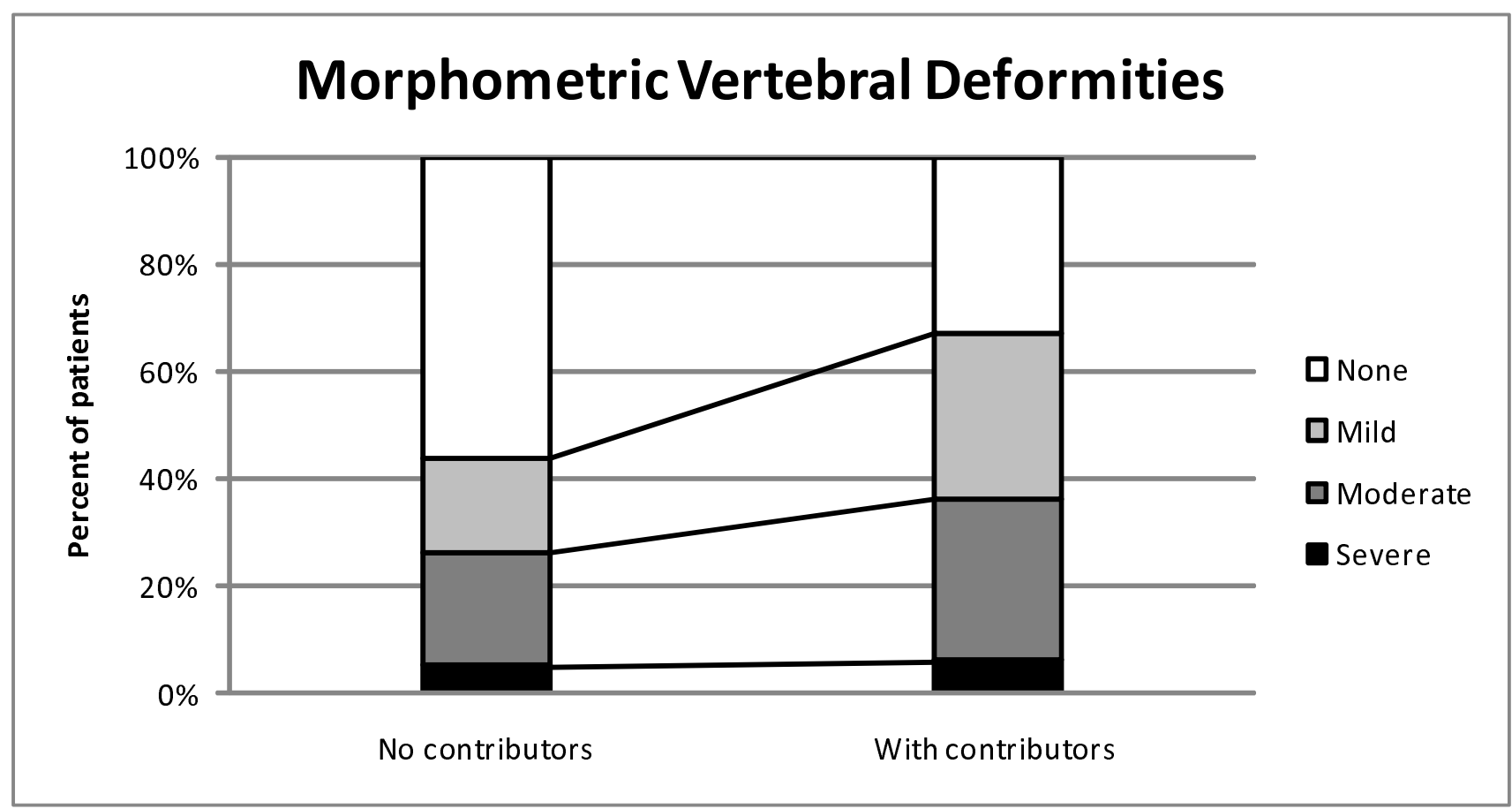

Figure 3

Prevalence of MVD defined according to the grading of Genant et al. in patients with contributors to secondary osteoporosis and in patients without contributors.

tosterone (in one man). Hyperthyroidism, whether endogenous or exogenous, can increases bone turnover and contributes to secondary osteoporosis $[37,38]$. Hypothyroidism on the other hand increases the risk of fractures through low bone turnover if untreated or high bone turnover if over treated [39]. Thus fine-tuning thyroid treatment is indicated. The same is probably true for patients with hypercalciuria in whom thiazides are indicated [40], and for hypogonadism in men that can be treated with testosterone supplementation [41], although no fracture prevention data are available in these conditions.

Therefore, measuring serum $25-\mathrm{OHD}_{3}$, calcium in 24 hours urine, serum creatinine, TSH, PTH as proposed by Tannenbaum et al. is indicated in patients with osteoporosis and a recent clinical fracture, and enabled us to identify 47 (96\%) newly diagnosed contributors and 13 of the 14 laboratory abnormalities [3]. As many patients had endocrine diseases, collaboration with endocrinologists appeared to be highly valuable for diagnosis and treatment.

The prevalence of clinical bone-related fracture risks in postmenopausal women, as evaluated by the Dutch guidelines, was similar between patients with and without documented contributors to and it contributed to further specify the risk for fractures.

Nearly $80 \%$ of patients had fall-related risk factors for fractures, as reported by others [16]. Although it has not been shown until now that fall prevention strategies itself can prevent fractures, they reduce the risk of falls. [42] A multidisciplinary, multifactorial intervention program reduces postoperative falls and injuries after femoral neck fracture and are therefore applied in our ongoing prevention program [43].

An interesting finding was the prevalence of MVD which was more than twice as high among patients with documented contributors for secondary osteoporosis compared to those without contributors, in spite of similar low BMD in both groups. MVDs, that are related to future fracture risk independent of BMD [11], reflect bone failure independently of BMD and thus indicate other mechanisms of bone's decreased resistance to fracture than low $\mathrm{BMD}$, such as changes in the bone turnover, alterations in micro architecture of bone and deficient mineralization, especially in the context of the high prevalence of calcium and vitamin $\mathrm{D}$ deficiency. 
In several recent publications differential diagnosis and search for contributors to secondary osteoporosis is advocated $[44,45]$. Only limited data are available about collaboration between surgeons and internists in taking care for osteoporosis in patients presenting with a fracture. Some initiatives were very successful [46], but in most instances the collaboration is failing [47]. This study indicates that such collaborations add to better treatment of patients with a clinical fracture.

This study has several limitations. Smoking history, which is part of the WHO FRAX tool, was not recorded as it is not part of the Dutch guideline. The sample size was relatively small, but the strength of the study was that consecutive patients were evaluated showing that even in a small group many contributors to secondary osteoporosis could be diagnosed. Some laboratory abnormalities needed further exploration, but were not followed up and so no definite diagnosis could be reported in these patients. VFA has several limitations. Not all vertebrae could be measured, mainly at the upper thoracic level. Identifying patients with MVD by VFA requires additional X-rays to differentiate deformities due to other conditions, such as Scheuerman's disease, degenerative changes or non-osteoporotic short vertebral height. However, the method has a high negative predictive value in predicting the absence of vertebral fractures on X-rays [27]. Another limitation is that only patients with BMD-osteoporosis were included. Most patients with a fracture have no BMD-osteoporosis. The results of our study suggest that documentation of the prevalence of contributors to secondary osteoporosis should also be studied in patients with a clinical fracture without BMD osteoporosis.

\section{Conclusion}

We conclude that more than one in two patients presenting with a clinical vertebral or non-vertebral fracture and BMD-osteoporosis have secondary contributors to osteoporosis, most of which were correctable. Identifying and correcting these associated disorders will enhance treatment effect aimed at reducing the risk of subsequent fractures in patients older than 50 years.

\section{Abbreviations}

BD: Bianca Dumitrescu; BMD: Bone mineral density; CI: confidence interval; DXA: Dual X-Ray absortiometry; ESR: Erythrocyte sedimentation rate; EULAR: European League against Rheumatism; FRAX: Fracture risk assessment tool; MEC: Medical Ethical Committee; MVD: Morphometric vertebral deformity; MVF: Morphometric vertebral fracture; OR: Odds ratio; PTH: Parathormone; TSH: Thyroid stimulating hormone; VFA: Vertebral fracture assessment; WHO: World Health Initiative.

\section{Competing interests}

The authors declare that they have no competing interests.

\section{Authors' contributions}

$\mathrm{BD}$ analyzed clinical and laboratory data for the diagnosis of contributors to secondary osteoporosis, performed vertebral fracture assessment, statistical analyses and wrote the manuscript. SvH implicated in the coordination of the study, involved in the treatment of patients included in the study, participated to sequence alignment and data presentation. RtB involved in the coordination of the study, involved in the treatment of patients included in the study. AN-K analyzed clinical and laboratory data for the diagnosis of contributors to secondary osteoporosis, coordinated data presentation. CW gathered laboratory and clinical data, performed statistical analysis. GU participated in the sequence alignment. SvdL analyzed clinical and laboratory data for the diagnose of contributors to secondary osteoporosis, coordinated data presentation. PG conceived the study, participated in the design of the study, coordinated the study, analyzed the data for correct diagnosis and drafted the manuscript.

\section{Acknowledgements}

EULAR: BD received a EULAR (European League against Rheumatism) grant for research in the field of osteoporosis at the University Hospital of Maastricht. This manuscript is part of her PhD thesis work.

Thank you to Gittie Willems, the osteoporosis nurse working at The Fracture and Osteoporosis Outpatient Clinic for her active involvement and for contributing to the data collection in this study.

\section{References}

I. van Helden S, van Geel AC, Geusens PP, Kessels A, Nieuwenhuijzen Kruseman AC, Brink PR: Bone and fall-related fracture risks in women and men with a recent clinical fracture. J Bone Joint Surg Am 2008/02/05 edition. 2008, 90(2):24I-248.

2. Geusens PP, Lems WF, Verhaar HJ, Leusink G, Goemaere S, Zmierczack $\mathrm{H}$, Compston J: Review and evaluation of the Dutch guidelines for osteoporosis. J Eval Clin Pract 2006, I 2(5):539-548.

3. Tannenbaum C, Clark J, Schwartzman K, Wallenstein S, Lapinski R, Meier D, Luckey M: Yield of laboratory testing to identify secondary contributors to osteoporosis in otherwise healthy women. J Clin Endocrinol Metab 2002, 87( I 0):443 I-4437.

4. Prevention and management of osteoporosis. World Health Organ Tech Rep Ser 2003, 92 I : I- I64, back cover.

5. Fitzpatrick LA: Secondary causes of osteoporosis. Mayo Clin Proc 2002, 77(5):453-468.

6. Edwards B], Langman CB, Bunta AD, Vicuna M, Favus M: Secondary contributors to bone loss in osteoporosis related hip fractures. Osteoporos Int 2008/01/09 edition. 2008.

7. NIH Consensus Development Panel on Osteoporosis Prevention, Diagnosis, and Therapy, March 7-29, 2000: highlights of the conference. South Med J 200I, 94(6):569-573.

8. Assessment of fracture risk and its application to screening for postmenopausal osteoporosis. Report of a WHO Study Group. World Health Organ Tech Rep Ser 1994, 843: I- 129.

9. Kanis JA, Geusens P, Christiansen C: Guidelines for clinical trials in osteoporosis. A position paper of the European Foundation for Osteoporosis and Bone Disease. Osteoporos Int 1991, I(3): $182-188$

10. Richtlijn Preventie van valincidenten bij ouderen. Utrecht, Kwaliteitsinstitut voor de Gezondheidszorg; 2004. 
1I. Siris ES, Genant HK, Laster AJ, Chen P, Misurski DA, Krege JH: Enhanced prediction of fracture risk combining vertebral fracture status and BMD. Osteoporos Int 2007, 18(6):76I-770.

12. Kanis A): WHO Fracture Risk Assessment Tool. february, 2008 edition. [http://www.shef.ac.uk/FRAX/].

13. Favus DMJ: PRIMER on the Metabolic Bone Diseases and Disorders of the Mineral Metabolism. In Best Pract Res Clin Rheumatol 12th edition. American Society for Bone and Mineral Research; 2006:1.

14. Wagman RB, Marcus R: Beyond bone mineral density-navigating the laboratory assessment of patients with osteoporosis. J Clin Endocrinol Metab 2002, 87( ( 0):4429-4430.

15. Deutschmann HA, Weger M, Weger W, Kotanko P, Deutschmann MJ, Skrabal F: Search for occult secondary osteoporosis: impact of identified possible risk factors on bone mineral density. J Intern Med 2002, 252(5):389-397.

16. Becker C, Crow S, Toman J, Lipton C, McMahon DJ, Macaulay W, Siris E: Characteristics of elderly patients admitted to an urban tertiary care hospital with osteoporotic fractures: correlations with risk factors, fracture type, gender and ethnicity. Osteoporos Int 2006, 17(3):410-416.

17. The role of calcium in peri- and postmenopausal women: 2006 position statement of the North American Menopause Society. Menopause 2006, 13(6):862-77; quiz 878-80.

18. Geusens PP: Review of guidelines for testing and treatment of osteoporosis. Curr Osteoporos Rep 2003, I(2):59-65.

19. Ismail AA, Cooper C, Felsenberg D, Varlow J, Kanis JA, Silman AJ, O'Neill TW: Number and type of vertebral deformities: epidemiological characteristics and relation to back pain and height loss. European Vertebral Osteoporosis Study Group. Osteoporos Int 1999, 9(3):206-213

20. Saile $P$, Fiedler R, Markau S, Kuhn C, Osten B: [Estimation of renal function in clinical routine: which is the best method?]. Dtsch Med Wochenschr 2007, I32(20): 1093-1097.

21. Dawson-Hughes B, Heaney RP, Holick MF, Lips P, Meunier PJ, Vieth R: Estimates of optimal vitamin D status. Osteoporos Int 2005 , 16(7):7|3-7|6.

22. Holick MF, Siris ES, Binkley N, Beard MK, Khan A, Katzer JT, Petruschke RA, Chen E, de Papp AE: Prevalence of Vitamin D inadequacy among postmenopausal North American women receiving osteoporosis therapy. J Clin Endocrinol Metab 2005, 90(6):3215-3224.

23. Heaney RP, Davies KM, Chen TC, Holick MF, Barger-Lux MJ: Human serum 25-hydroxycholecalciferol response to extended oral dosing with cholecalciferol. Am J Clin Nutr 2003 , 77(1):204-210.

24. Nieschlag E, Swerdloff R, Behre HM, Gooren LJ, Kaufman JM, Legros JJ, Lunenfeld B, Morley JE, Schulman C, Wang C, Weidner W, Wu FC: Investigation, treatment and monitoring of late-onset hypogonadism in males: ISA, ISSAM, and EAU recommendations. Int J Androl 2005, 28(3): I25-I27.

25. Bailie GR, Massry SG: Clinical practice guidelines for bone metabolism and disease in chronic kidney disease: an overview. Pharmacotherapy 2005, 25(I 2): | 687-I707.

26. Shaw $A D$, Davies $G$ J: Lactose intolerance: problems in diagnosis and treatment. I Clin Gastroenterol 1999, 28(3):208-216.

27. Lewiecki EM, Laster AJ: Clinical review: Clinical applications of vertebral fracture assessment by dual-energy $x$-ray absorptiometry. J Clin Endocrinol Metab 2006, 9 I (I I):4215-4222.

28. Genant HK, Li J, Wu CY, Shepherd JA: Vertebral fractures in osteoporosis: a new method for clinical assessment. J Clin Densitom 2000, 3(3):28I-290.

29. Genant HK, Wu CY, van Kuijk C, Nevitt MC: Vertebral fracture assessment using a semiquantitative technique. J Bone Miner Res 1993, 8(9): | |37-| | 48 .

30. McAlindon TE, Felson DT, Zhang Y, Hannan MT, Aliabadi P, Weissman B, Rush D, Wilson PW, jacques P: Relation of dietary intake and serum levels of vitamin $D$ to progression of osteoarthritis of the knee among participants in the Framingham Study. Ann Intern Med 1996, I 25(5):353-359.

31. Boonen S, Bischoff-Ferrari HA, Cooper C, Lips P, Ljunggren O, Meunier PJ, Reginster JY: Addressing the musculoskeletal components of fracture risk with calcium and vitamin D: a review of the evidence. Calcified tissue international 2006, 78(5):257-270.
32. Boonen S, Vanderschueren D, Haentjens P, Lips P: Calcium and vitamin $D$ in the prevention and treatment of osteoporosis a clinical update. Journal of internal medicine 2006, 259(6):539-552.

33. $\mathrm{B} D H$ : The role of vitamin $\mathbf{D}$ in fracture prevention. BoneKEyOsteovision 2005, 2(46-10 [http://www.bonekey-ibms.org/content/ vol2/issue4]

34. Heaney RP: The Vitamin $D$ requirement in health and disease. J Steroid Biochem Mol Biol 2005, 97( I-2): I3-19.

35. Chapuy MC, Schott AM, Garnero P, Hans D, Delmas PD, Meunier PJ: Healthy elderly French women living at home have secondary hyperparathyroidism and high bone turnover in winter. EPIDOS Study Group. J Clin Endocrinol Metab 1996, 8I(3): I I29-II I33

36. Bischoff HA, Stahelin HB, Dick W, Akos R, Knecht M, Salis C, Nebiker M, Theiler R, Pfeifer M, Begerow B, Lew RA, Conzelmann M: Effects of vitamin $D$ and calcium supplementation on falls: a randomized controlled trial. J Bone Miner Res 2003, I 8(2):343-35I.

37. Bauer DC, Ettinger B, Nevitt MC, Stone KL: Risk for fracture in women with low serum levels of thyroid-stimulating hormone. Ann Intern Med 200I, I34(7):56I-568.

38. Vestergaard P, Mosekilde L: Hyperthyroidism, bone mineral, and fracture risk--a meta-analysis. Thyroid 2003, I 3(6):585-593

39. Vestergaard P, Rejnmark L, Mosekilde L. Influence of hyper- and hypothyroidism, and the effects of treatment with antithyroid drugs and levothyroxine on fracture risk. Calcif Tissue Int 2005, 77(3): |39-144.

40. Liebman SE, Taylor JG, Bushinsky DA: Idiopathic hypercalciuria. Curr Rheumatol Rep 2006, 8(I):70-75.

4I. Nieschlag E, Swerdloff R, Behre HM, Gooren LI, Kaufman JM, Legros JJ, Lunenfeld B, Morley JE, Schulman C, Wang C, Weidner W, Wu FC: Investigation, treatment, and monitoring of late-onset hypogonadism in males: ISA, ISSAM, and EAU recommendations. J Androl 2006, 27(2): I35-I37.

42. Chang IT, Morton SC, Rubenstein IZ, Mojica WA, Maglione M, Suttorp MJ, Roth EA, Shekelle PG: Interventions for the prevention of falls in older adults: systematic review and meta-analysis of randomised clinical trials. Bmj 2004, 328(744I):680.

43. Stenvall M, Olofsson B, Lundstrom M, Englund U, Borssen B, Svensson $\mathrm{O}$, Nyberg L, Gustafson Y: A multidisciplinary, multifactorial intervention program reduces postoperative falls and injuries after femoral neck fracture. Osteoporos Int 2007, I8(2): $167-175$

44. US Department of Health and Human Services : 2004 Surgeon General's Report on Bone Health and Osteoporosis: What It Means To You. 2004, : [http://www.surgeongeneral.gov/library/ bonehealth/docs/OsteolOsep04.pdf]

45. Kanis JA, Burlet N, Cooper C, Delmas PD, Reginster JY, Borgstrom $F$, Rizzoli R: European guidance for the diagnosis and management of osteoporosis in postmenopausal women. Osteoporos Int 2008/02/13 edition. 2008, I9(4):399-428.

46. Chevalley T, Hoffmeyer P, Bonjour JP, Rizzoli R: An osteoporosis clinical pathway for the medical management of patients with low-trauma fracture. Osteoporos Int 2002/07/II edition. 2002, I3(6):450-455

47. Feldstein AC, Nichols GA, Elmer PJ, Smith DH, Aickin M, Herson M: Older women with fractures: patients falling through the cracks of guideline-recommended osteoporosis screening and treatment. J Bone Joint Surg Am 2003/I2/12 edition. 2003, 85A(I 2):2294-2302.

\section{Pre-publication history}

The pre-publication history for this paper can be accessed here:

\section{http://www.biomedcentral.com/1471-2474/9/109/pre} pub 